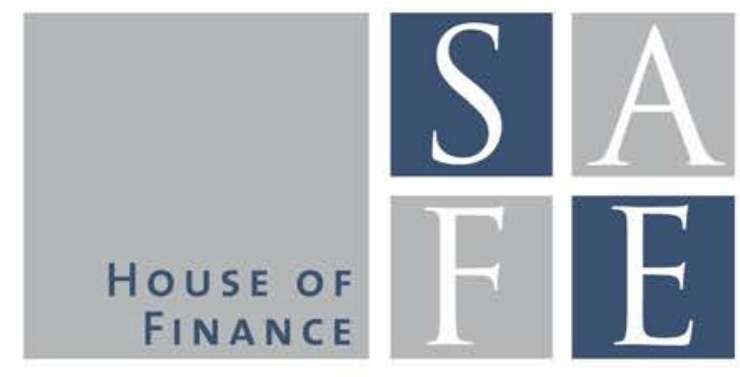

WORKINg PAPER SERIES

Horst Entorf - Jia Hou

\title{
Financial Education for the Disadvantaged? A Review
}

SAFE Working Paper No. 205

SAFE I Sustainable Architecture for Finance in Europe A cooperation of the Center for Financial Studies and Goethe University Frankfurt 


\section{Non-Technical Summary}

Many researchers and politicians have identified a lack of financial literacy among the disadvantaged groups of the society. Thus, unequal access to financial markets seems to be a major source of economic inequality, and tackling inequality by starting financial education initiatives seems to be a straightforward solution. However, in contrast to the popularity of financial education interventions worldwide, studies on the economic effects of those interventions report mixed results.

With a focus on the effect of disadvantaged groups, we review both the theoretical and empirical findings in order to understand why this discrepancy exists. The survey highlights that it is necessary to distinguish between the concepts of financial education, financial literacy and financial behavior in order to disentangle cause and effect. To understand the heterogeneity of potential outcomes, we review theoretical explanations which address the effect of interventions across the population and over the life cycle. Looking at empirical results, we discuss the importance of potentially neglected factors such as cognitive ability, mathematical capability or numeracy, and we find that the young, the immigrants/migrants and the low-income groups obtain more attention from scholars than other disadvantaged groups. Some support in favor of financial education for the young has been detected in terms of higher short-term financial knowledge and awareness, but there is no proven evidence of improved long-term behavior after growing up. From the methodological point of view, in recent years randomized control trials (RCT) have become a popular method to evaluate the effects of financial education, in particular for studies on remittance behavior of migrants. Our review discusses some limitations of both RCTs and econometric studies which might be taken into account by future research.

In sum, despite the enthusiasm of many politicians, who see financial education and financial literacy as the key to tackle the problem of financial vulnerability and economic inequality, so far, there is no clear evidence, or at least no scientific consensus, on the effectiveness of performed interventions. The constant search for effective financial education might even cost enormously such that the costs of financial education programs would outweigh potential benefits. It is perhaps true that the financial behavior of the poor is arguably more controlled by lack of aspirations such that financial policy should be directed towards behaviorally motivated anti-poverty policies or simply education in general. 


\title{
Financial Education for the Disadvantaged? A Review*
}

\author{
Horst Entorf ${ }^{\dagger}$ \\ Goethe University Frankfurt and SAFE \\ Jia $\mathrm{Hou}^{\ddagger}$ \\ Goethe University Frankfurt and SAFE
}

This Version: 20 April 2018

\begin{abstract}
In contrast to the popularity of financial education interventions worldwide, studies on the economic effects of those interventions report mixed results. With a focus on the effect on disadvantaged groups, we review both the theoretical and empirical findings in order to understand why this discrepancy exists. The survey first highlights that it is necessary to distinguish between the concepts of, and the relationships between, financial education, financial literacy and financial behavior to identify the true effects of financial education. The review addresses possible biases caused by third factors such as numeracy. Next, we review theories on financial literacy which make clear that the effect of financial education interventions is heterogeneous across the population. Last, we look closely at main empirical studies on financial education targeted at the migrants/immigrants, the low-income earners and the young, and compare their methodologies. There seems to be a positive effect on short-term financial knowledge and awareness of the young, but there is no proven evidence on long-term behavior after being grown up. Studies on financial behavior of migrants and immigrants show almost no effect of financial education.
\end{abstract}

JEL Code: G28, G41, I24, I25, I28

Key words: Financial Education, Financial Literacy, Inequality, Program Evaluation

\footnotetext{
${ }^{*}$ We are grateful to the LOEWE Center Sustainable Architecture for Finance in Europe (SAFE) program for financial support of our research.

${ }^{\dagger}$ Corresponding author: Goethe University Frankfurt, Faculty of Economics and Business Administration, Theodor-W.-Adorno-Platz 4, 60323 Frankfurt, Germany. Email: entorf@wiwi.unifrankfurt.de.

${ }^{\ddagger}$ Goethe University Frankfurt, House of Finance, 60323 Frankfurt, Germany. Email: hou@safe.uni-frankfurt.de.
} 


\section{Introduction}

In the last two decades, financial education has gained much attention from policy makers around the world. As noted by OECD (2015b), 59 countries are reported to be developing a national strategy for financial education by 2015. For instance, financial education has been compulsory on the national curriculum in England since 2014 , after a petition with more than 100,000 signatures was submitted for the debate in 2011. In the U.S., a "Financial Literacy and Education Improvement Act" was part of the "Fair and Accurate Credit Transactions Act" of 2003 to develop a national financial education strategy. In the European Union, in its 2008 resolution on improving consumer education and awareness on credit and finance, the European Parliament noted that raising the level of financial literacy of consumers should be a priority for policy-makers, both at the Member State and the European leve!

Studies on financial literacy have confirmed the importance of financial knowledge on the individual's personal finance $\mathrm{2}^{2}$ and economic outcome $\mathrm{s}^{3}$. The worldwide 2008 financial crisis reveals that individuals' ability to face the crisis is different according to their financial literacy (for example, Klapper et al. (2013)). It is then intuitive to think that financial education is critical to individuals' welfare or to protect them from economic crisis, since financial education is supposed to improve the financial knowledge of the individual and eventually to improve the resilience of the economy. If so, does financial education affect financial behavior through the channel of financial literacy? Are financial knowledge and, more importantly, financial behavior, really affected by financial education, or is it more reasonable to assume that third factors such as numeracy of mathematical capabilities play the leading role? Why are the empirical findings on the effects of financial education so mixed while financial education interventions remain so popular? Is it possible that financial education policy is just an excuse and loophole for politicians who do not want to forego any opportunity to avoid being accused of any future financial crisis,

\footnotetext{
${ }^{1}$ http: //www . europarl europa $\cdot$ eu/sides/getDoc $\cdot$ do?type=TA\&language=EN\&ref erence= P6-TA-2008-539.

${ }^{2}$ For example, Hastings et al. (2013) list behavior related to credit card spending, holding stocks, bonds, mutual funds or other securities, loans (e.g., making late payments on a mortgage, comparison shopping for a mortgage or auto loan), insurance coverage, financial counselling (e.g., seeking professional advice about a mortgage, loan, insurance, tax planning, or debt counselling). A different focus includes impacts on portfolio choice (Campbell (2006), Von Gaudecker (2015)) and saving and borrowing (Gathergood (2012)).

${ }^{3}$ For example.Van Rooij et al. (2011) on stock market participation and Disney and Gathergood (2013) on consumer portfolios. Please see Lusardi and Mitchell (2014) and Hastings et al. (2013) for a more extensive review.
} 
whatever the (unknown) cost: $4^{4}$ of such strategy? This survey aims at answering these questions by reviewing the current literature.

Our contribution is threefold. Firstly, we distinguish between the concepts of financial education, financial literacy (or financial knowledg $€^{5}$, respectively), and financial behavior, and we define and consider the three concepts of being in a logical order. We start by highlighting the link between financial education interventions and measured financial knowledge/literacy and go from there to (good or bad) financial decision making of individuals and households. We discuss research results which lead to question the causal influence of financial education on behavior, because other factors such as mathematical ability might be likewise important, rendering the influence of financial education on outcomes as a potentially spurious one.

Secondly, this survey is the first to review theories on financial education. Theories on financial literacy, which incorporate the accumulation process of financial literacy, are the most relevant ones. The human capital accumulation model and endogenous investment model of financial literacy imply that different groups of people are in heterogeneous need of financial education.

Thirdly, we take account of the heterogeneity of financial education interventions and provide a review targeted at disadvantaged groups. As recognized by the OECD, young people (more than half of the responding countries in the OECD survey), women, low-income groups, elderly people, micro-, small-, and medium-sized enterprises, migrants and, in a few countries, people living in rural areas, are targeted groups of importance for financial education strategies (OECD (2015b)).

Different from comprehensive meta-analysis by Fernandes et al. (2014), Miller et al. (2015) and Kaiser and Menkhoff (2017), we review research papers on a studyby-study basis in order to focus on those studies which allow us to gain some knowledge on the impact of financial education on groups at the bottom of financial inequality. Moreover, we analyze methodological discrepancies, which are often related to the question whether randomized control trials (RCT) are applied or not.

We find that the young, the immigrants/migrants and the low-income groups obtain more attention from scholars than other groups. Studies on large-scale samples, both using RCTs or econometric methods for quasi-experiments, show up more of-

${ }^{4}$ Willis (2011) criticizes the over-support from politics on for financial education and its "time, money, privacy, and autonomy costs".

${ }^{5}$ As in Lusardi and Mitchell (2014), we use the expression "financial knowledge" as a synonym. 
ten for investigating financial education of the young. For the immigrants/migrants, the effect on remittance behavior is the focus. Besides, it is worth of noting that each RCT or quasi-experiment we study is faced with some limitations, which we would like to discuss and which might be taken into account by future studies.

The survey is organized as follows. Section 2 discusses the link between financial education, financial literacy and financial behavior, and draws attention to the importance of third-factor influences. Section 3 summarizes theoretical foundations of financial literacy. Section 4 reviews the empirical findings regarding the influence of financial education interventions on disadvantaged groups, mainly the immigrants/migrants, the low-income groups and the young. Section 5 summarizes the survey and offers some conclusions.

\section{Financial Behavior: Financial Education, Fi- nancial Literacy, Numeracy or Just Education?}

The literature of interest is split between evaluating the effects of financial education on either the targeted financial behavior or on financial knowledge. For example, the criticism on policy-driven financial education by Willis (2011) starts with the argument that "objective observers generally admit that research to date does not demonstrate a causal chain from financial education to higher financial literacy to better financial behavior to improved financial outcomes", which implicitly defines that an effective financial education should be an intervention able to eventually improve financial behavior. However, Fernandes et al. (2014) refer to financial education interventions directly as "manipulated financial literacy". Unclear intentions of financial education might blur findings from the literature. We would like to avoid such conceptual ambiguity and therefore consider financial literacy (and financial knowledge) as a means to an end, but not the end itself. Nevertheless, "financial literacy", per se, plays the more glamorous role in many research articles such that a review of the literature would be incomplete without them.

\subsection{Financial Education and Financial Literacy}

Actually, the definition of financial literacy has evolved over time (Huston $(2010))$, but still with no convergence. Lusardi and Mitchell (2014), perhaps the most prominent contributors to the field of study, refer to financial literacy as "peoples' ability to process economic information and make informed decisions about financial plan- 
ning, wealth accumulation, debt, and pensions". Financial literacy can then be used interchangeably with "financial knowledge", which affects individuals' financial behavior or economic outcomes. Each individual is motivated differently to accumulate her/his financial literacy based on the cost and return of financial literacy over the life cycle. In this context, the effects of financial education are suggested to be heterogeneous by age and income level, etc. The OECD, one of the most active organizations in promoting the awareness of financial literacy and financial education, use a more target-based concept by directly focusing on the purpose of financial literacy, i.e., "financial inclusion". Their proposed measurement "toolkit" incorporates capturing "... information about financial behavior, attitudes and knowledge, in order to assess levels of financial literacy and financial inclusion" (OECD (2015a)).

Most literature reveals a strong link between financial literacy and poor or smart financial decision making, whereas the causal influence of financial education on financial knowledge or even financial decision making is less clear, as has been documented in detail by Hastings et al. (2013), Fernandes et al. (2014) and Lusardi and Mitchell (2014), among many others. There are several reasons for contradictory assessments of the effects of financial education. For instance, studies are usually based on different target groups or different methodological approaches, where the use or nonuse of random control trials (RCT) is of increasing importance (see Hastings et al. (2013), Lusardi and Mitchell (2014), or Kaiser and Menkhoff (2017)).

A substantial part of the debate on the effectiveness of financial education is linked to the way how researchers define and measure financial literacy itself. Hung et al. (2009) document the breadth of existing conceptual definitions, ranging from financial knowledge and familiarity with financial terms to the capability of making informed judgements. As also noticed by Lusardi and Mitchell (2014) and Xu and Zia (2012), many studies follow Hilgert et al. (2003), Lusardi and Mitchell (2008), Lusardi et al. (2010) etc., and measure financial literacy with respondents' correct answer to the "big three" questions on inflation, interest rate and risk aversion. With the efforts of those studies, more national surveys build on those questions when measuring financial literacy of households ${ }^{6}$ (e.g., the Panel on Household Finance of Germany, the Health and Retirement Study and National Financial Capability Study of the U.S.). Additional financial literacy questions like questions on mortgages and bond pricing are also included in some studies.

However, how valid those questions and correct answers are for capturing the

\footnotetext{
${ }^{6}$ Please see Lusardi and Mitchell (2011), Hastings et al. (2013), Xu and Zia (2012) for comparisons of financial literacy measured by the "big three" around the world.
} 
true financial knowledge is still under debate, letting alone the variation caused by different methods of obtaining the information (such as online surveys or telephone interviews) or ways of rating the knowledge (e.g., Huston (2010)). Schuhen and Schürkmann (2014) indicate that the reason why Germany refused to participate in the OECD-PISA assessment of financial literacy ${ }^{7}$ is that "the current version of a Financial Literacy assessment is not sufficiently developed and reliable findings are therefore not possible".

\subsection{Neglected Factors in the Analysis of Financial Behavior}

The work by Willis $(2008,2011)$ has gained much attention for its harsh criticism of financial education policy and for casting serious doubt on the widespread belief in the effectiveness of financial education (she also employs the combined term "financial literacy education"). She argues that the gulf between literacy and useful decisions on financial products cannot realistically be bridged, for instance, because new products are often highly complex and changing over time such that financial literacy education would mean chasing a moving target it would never reach. On the contrary, outdated lessons or financial rules of thumb may not only be irrelevant, but even counterproductive. She refers to the problem that financial education appears to increase confidence without improving ability, i.e., overconfidence, potentially leading to worse decisions. This is in line with recent research by Von Gaudecker (2015), who finds that most losses from lacking diversification are incurred by overconfident investors. McCannon et al. (2016) show that overconfident clients, who believe they possess more knowledge and understanding than they actually do, lead investors to underestimate risks and shortcomings of certain investment options, although results by Hackethal et al. (2012) suggest that such biased behavior seems to diminish with experience.

Other researchers identify potentially omitted variables when linking financial literacy, financial education, and financial decision making. A recent paper by Gramatki (2017) suggests that measured financial literacy could just reflect mathematical capacity. Using the first OECD PISA (2012) international assessment of financial literacy, Gramațki (2017) finds that the financial literacy gap between native and immigrant students is significant, but not after controlling for students' math score. Hung et al. (2009) point out that many concepts, such as the ability to work with numbers, i.e., numeracy, share features with financial literacy. They also

\footnotetext{
${ }^{7}$ The Program for International Student Assessment (PISA) is an international project conducted by OECD to analyze the financial literacy of adolescents aged 15-16 in the member states. In 2012 and 2015, 18 countries and 16 countries participated in the assessment, but not Germany.
} 
describe other factors such as general knowledge, cognitive abilities and decisionmaking competence and their relationship to financial literacy. The skill captured by the standard financial literacy question on, say, compound interest might just be an indicator of general numeracy skills rather than financial literacy. After including numeracy, the capability of long-term planning, willingness to take prudent investment risks, and confidence with respect to marketplace decisions, Fernandes et al. (2014) show that financial literacy ceases to be significant in most of the presented regressions. The authors correctly mention different interpretations of their results. The argument against financial literacy would be that third factors cause financial behavior, such that financial literacy would only be seemingly related to good or bad financial decisions. However, their results do not preclude the opposite interpretation that included covariates are endogenous and caused by financial literacy.

The obvious question is what matters most for good financial decision making and behavior. Perhaps it is just education? Cole et al. (2014) study the causal effects of education on asset accumulation and financial market participation, where they use changes in state compulsory education laws as an instrument for educational attainment. Their results are also in line with the hypothesis that the link between education and financial outcomes is indirect, as education improves cognitive ability (see Hanushek and Woessmann (2008)) and cognitive ability appears to improve financial outcomes. Thus, despite the strong link between education and

financial literacy (Lusardi and Mitchell (2014)), the correlation between financial literacy and financial outcomes might not be a causal one, but caused by the joint dependence on education, particularly in maths skills. This calls into question the effectiveness and efficiency of (costly) financial education policies.

However, before jumping to conclusions, we should have a better theoretical understanding of the effects of financial education interventions. Moreover, financial education programs can be tailored to the specific needs of target groups such that there might be group-specific outcomes and simple one-fits-all conclusions might not exist.

\section{Theoretical Foundations of Effects of Financial Education Interventions}

Financial education can be seen as a particular type of education which can be subsumed under the theory of human capital formation. Here, financial education is usually seen as a driver of financial literacy (which also means financial knowledge, 
as defined by Lusardi and Mitchell (2014)).

\subsection{Financial Education to Accumulate Financial Literacy as Human Capital}

Delavande et al. (2008) propose a two period life cycle model of financial knowledge on retirement saving and portfolio choice. Departing from the model of Kézdi and Willis (2008), which is due to the optimal portfolio choice model of Merton (1969), Delavande et al. (2008) assume that there is heterogeneity in people's knowledge about financial markets and thus not all of them can construct the optimal portfolio choices. More financial knowledge enables the individual to make better financial decisions. The accumulation of financial knowledge follows the human capital production function proposed by Ben-Porath (1967) and later developed by Cunha and Heckman (2007).

In the model of Delavande et al. (2008), financial knowledge is accumulated in a Cobb-Douglas way 8 .

$$
\Delta f_{t}=\frac{d f_{t}}{d t}=\alpha\left(e_{t} f_{t}\right)^{\beta_{1}} H_{t}^{\beta_{2}} M_{t}^{\beta_{3}} E_{t}^{\beta_{4}} ; \quad \beta_{1}+\beta_{2}+\beta_{3}+\beta_{4}<1,
$$

where $\Delta f_{t}$ is the financial knowledge obtained in the period $\mathrm{t}, e_{t}$ is effort devoted to learning, $f_{t}$ is the stock of financial knowledge at the beginning of a period, and $e_{t} f_{t}$ is the number of efficiency units in time invested in obtaining financial knowledge. With this production model, financial knowledge is self-productive and the efficiency of obtaining financial knowledge in the future can be enhanced by disposing of higher current financial knowledge stock. Besides, the productivity of investment in learning financial knowledge is dependent on other factors captured by $H_{t}, M_{t}, E_{t}$, such as the stock of other human capital, the knowledge of family and friends etc.

The model implies that those people who have lower inputs in $H_{t}, M_{t}, E_{t}$ need more help from public financial education interventions since they need more time in obtaining the same financial knowledge. However, the model does not say too much about the efficiency of financial education interventions in different institutional settings, such as more or less generous social security systems. Besides, it is not clear yet what is in $H_{t}, M_{t}, E_{t}$.

In order to explain the heterogeneity of beliefs observed by the American Health

\footnotetext{
${ }^{8}$ This is equation (4) in Delavande et al. (2008). We change some of the notations for the
} consistency of this survey, similarly for the following equations. 
and Retirement Study about the stock market, Kézdi and Willis (2011) propose a three-period life-cycle model of financial knowledge. The model suggests that those who have higher lifetime earnings, higher risk tolerance, and more patience are those who are more motivated to obtain financial knowledge. The implication on financial education interventions is two-fold. On one hand, financial education interventions will be more attractive to those who are more motivated to obtain financial knowledge. On the other hand, those who are less motivated to obtain financial knowledge need more exogenous financial education interventions. The model of Kézdi and Willis (2011) can be seen as an application of Delavande et al. (2008).

\subsection{Financial Education to Accumulate Financial Literacy as Endogenous Choice Variable}

In a framework different from the one incorporating financial literacy into human capital accumulation, Jappelli and Padula (2013) propose a consumption model of consumer investment in financial literacy based on Arrow (1987). In the model, financial literacy can increase the return on wealth, but also costs in terms of current consumption and it decays over time. In the multi-period case, financial literacy evolves as the following?

$$
\begin{gathered}
\left(i-\alpha \frac{s_{t}}{f_{t+1}}\right) f_{t+1}^{\alpha}-i(1-\delta)=0 \quad \text { for } \quad t \leq T-3 \\
i-\alpha \frac{s_{t}}{f_{t+1}}=0 \quad \text { for } \quad t=T-2,
\end{gathered}
$$

where $\mathrm{i}$ is the cost of financial literacy in terms of consumption good, $s_{t}$ is the saving at period t. $\alpha$ is the return on the stock of financial literacy, $f_{t+1}$. The financial literacy depreciates at the rate of $\delta$.

The model implies that both financial literacy and wealth are endogenous and strongly correlated with each other over the life cycle. An interesting prediction of the model of Jappelli and Padula (2013) is that in countries with a more generous social security system, investors will be less motivated to accumulate financial literacy. This feature hints at an interesting source of international heterogeneity of financial literacy. It further indicates that the need for financial education interventions might depend on country characteristics such as the prevailing social security system.

\footnotetext{
${ }^{9}$ These are equation (8) and (9) in Jappelli and Padula (2013).
} 
More recently, Lusardi et al. (2017) develop a stochastic life cycle model of financial knowledge. The model follows the line of Jappelli and Padula (2013), but extends it by incorporating many features such as borrowing constraints, mortality risk, demographic factors, stock market returns, and earnings and health shocks, which brings it closer to the standard model of saving (Lusardi and Mitchell (2014)). As in Jappelli and Padula (2013), the model is based on the assumption that financial knowledge is acquired endogenously over the life cycle.

The model is described by a intertemporal value function, which is subject to borrowing constraints. Financial literacy at period $t+1, f_{t+1}$, costs $\left(i_{t}\right)$ and decays $(\delta)$ :

$$
f_{t+1}=(1-\delta) f_{t}+i_{t}
$$

but it increases the stochastic return on risky assets. The model is solved by numerically by using backward recursion method. To calibrate the effects of endogenous financial knowledge on the wealth inequality, Lusardi et al. (2017) impose value on parameters based on previous studies including Hubbard et al. (1995), Attanasio (1999) and Scholz et al. (2006).

Several predications based on different sources of uncertainty can be drawn from the model. An important one is that financial education interventions affect subgroups of the population differently. Participants who find it not optimal to save more, such as the low educated and low-income group, might cause the ineffectiveness of financial education interventions targeted at improving saving. It is then necessary to design special financial education interventions in a way that increases the participation rate of those groups.

To extend the standard two-period model, Lusardi et al. (2017) take the following steps: (1) introducing uncertainty regarding asset returns, household income, and out-of-pocket medical expenditures; (2) including stochastic mortality risk for individuals; (3) examining different education groups. The simulation study based on various settings offers a large variety of implications which rationalize some of the large differences in wealth found in much prior empirical works on saving. The results also show that some level of financial ignorance may actually be optimal. For those who cannot benefit from the financial knowledge and greater financial sophistication, costs of acquiring financial education will exceed its benefits.

Overall, theories of financial literacy illustrate its accumulation process and provide a potential leverage point for improving the efficiency of financial education 
interventions. The model of Delavande et al. (2008) incorporates financial literacy into a human capital accumulation function. In their framework, financial literacy is exogenous and determined by investment and many other factors such as social network and cognitive ability. In contrast, Jappelli and Padula (2013) and Lusardi et al. (2017) model wealth and financial literacy as endogenous choice variables. The open question is what are the crucial third factors driving the endogenous cycle.

Given the financial behavior of agents is well-understood and fully covered, the models have much power in explaining the saving behavior and wealth. Endogeneity of financial knowledge certainly is a realistic assumption, but effective implementation of financial education seems to require the use of "teachable moments" which would imply some "just-in-time education". For example, after receiving a bequest, when taking out a mortgage, when figuring out when to retire, or when graduate students realize the importance of financial knowledge after graduating and receiving the first paycheck, income and capital earners might become very motivated to obtain knowledge. Of course, theoretical modeling does not deliver the identification of such turning points of life, the analysis and evaluation of those "trigger points" remains an empirical question. However, theory helps us to understand the shortand long-run and highly heterogeneous consequences of interventions on wealth accumulation.

Willis (2008) is even skeptical that offering financial education at a teachable moment, which also needs to be a "reachable" moment, has a lasting effect and that people are more likely to learn about personal finance. Empirical evidence from a large meta study by Kaiser and Menkhoff (2017) suggests that offering financial education at a teachable moment indeed shows significant overall effects, but teaching low-income groups has less impact. Thus, effects of financial education seem to be subject to target-group influence.

\section{Quantifying the Effects of Financial Education}

Compared with the rather limited theoretical work, there is an increasing number of empirical studies on the effects of financial education. Using Google Search, the search for "financial education empirical research paper pdf" delivers about 43,200 hits (01 April 2018). Not surprisingly, the existing research delivers a large data base for recent meta-studies on financial education which we are going to survey in the next subsection. We also focus on (treatment) effects for disadvantaged groups and we particularly draw the attention to differences between random control trials 
(RCT) and non-RCT studies.

\subsection{Evidence from Meta Studies}

Two comprehensive meta studies, Fernandes et al. (2014) and Kaiser and Menkhoff (2017), conclude that financial education interventions only seem to have a substantially small impact on the financial behavior of disadvantaged groups. As it is challenging and not without irony to provide a survey on meta studies, we approach this task from a different angle and mainly review methodological particularities.

Meta-studies give a summary of the direction and magnitude of parameter estimates for a well-defined and narrowed research question. Measurement of "effect sizes" is the key to meta-analysis. They measure and weigh all available and comparable estimations within and across studies. From systematic methodological research on meta-analysis (see Lipsey and Wilson (2001), who published a leading textbook) we know that there are many definitions of effect sizes such as the standardized mean difference, Cohen's d, Cohen's w, the Odd's Ratio, Hedge's g, and the partial correlation r. Different meta-analytic studies use different definitions such that comparisons between different meta-analysis are difficult.

This is also true for Fernandes et al. (2014) and Kaiser and Menkhoff (2017), who systematically summarize the conclusions based on 77 and 126 studies, respectively. They analyze the effect of financial education on financial behavior and decisions ${ }^{10}$. Fernandes et al. (2014), using partial $\mathrm{r}$ as effect size indicator, report that financial education explains only $0.1 \%$ of the variance in financial behaviors studied (deduced from a calculated average partial $r=0.032$ ). They consider the (statistically significant) partial $r$ of 0.032 as being very small, because "By social science and education conventions, $r<0.10$ is a small effect size, $0.10<r<0.40$ is medium, and $r>0.40$ is large." Unfortunately, the authors do not quote any reference for this rule of thumb for the partial $r$ which, to the best knowledge of the authors of this survey, has not been covered by known guidelines such as the ones by Cohen (1992) and subsequent papers. The partial $R^{2}$ (or partial $\mathrm{r}$ ) is a problematic concept because it heavily depends on the number and explanatory power of already included control variables ${ }^{11}$. A model estimation plagued by omitted variable bias would create a

\footnotetext{
${ }^{10}$ Both studies also comprise the link between financial literacy and financial performance which is not covered here, as research indicates that it is most likely plagued by endogeneity problems.

${ }^{11}$ Fernandes et al. (2014) mention a long list of controls including saving, planning for retirement, absence of debt, stock ownership and investment decisions, cash flow management, activity in retirement plans, and financial inertia such as choice of default options and payment of unnecessary
} 
high partial improvement of the model fit, whereas well-designed studies with an extensive list of control variables only show small "effects" after including financial education instruments.

Different from Fernandes et al. (2014), Kaiser and Menkhoff (2017) use Hedge's $\mathrm{g}$ as effect size. As Cohen's d, this is a standardized mean difference between educated and non-educated groups, but with some bias correction for the standardizing standard error. Cohen (1992) considers such effect sizes as "small" when they are smaller than 0.20 , effect sizes around 0.50 indicate a "medium effect" and effect sizes exceeding 0.80 represent "large effect: ${ }^{12}$.

Not with standing the usefulness of such simple rules, already the difference between used rule-of-thumb-levels in both studies indicates that effect sizes should not be directly compared. Kaiser and Menkhoff report the overall result that financial education has an average effect size of $\mathrm{g}=0.086$ on financial behavior, using a sample of 349 effect sizes reported by 90 studies. Thus, according to the usual standards of standardized differences, the impact of financial education on financial behavior can be considered as "small". Kaiser and Menkhoff (2017, p.9) comment their average effect size of $\mathrm{g}=0.086$ as being "more favorable" than the one by Fernandes et al. (2014). However, as described above, effect sizes are not directly comparable such that the reason for their conclusion remains unclear.

Summing up the main findings of both meta analysis, the overall result is that included studies reveal a statistically significant yet substantially small impact of financial education on financial behavior. However, the interpretation of overall averages is limited. As likewise stated by Miller et al. (2015), the great heterogeneity of results makes it impossible to calculate a meaningful effect size as a general benchmark. Both meta-studies, especially the one by Kaiser and Menkhoff (2017), also look at different subsamples of which the subsample of low-income is of primary interest for this survey. Both studies find that for the low-income group the size effect is even significantly below the (small) average effect. In the Kaiser and Menkhoff paper, the effect would be reduced to $g=0.02(0.086-0.065$, see Table 3 in Kaiser and Menkhoff (2017)), and Fernandes et al. (2014) report a low-income specific partial $\mathrm{r}$ of 0.025 .

The best way to evaluate the effects of financial education interventions is to compare the difference of financial outcomes between randomly allocated "treated" and fees.

${ }^{12}$ This rule is also quoted by Kaiser and Menkhoff (2017). 
"control" groups (Collins and O'Rourke (2010)). According to Kaiser and Menkhoff (2017, Table 3), the estimated effect sizes of all included RCTs is $\mathrm{g}=0.016$ (0.086 0.070). Results by Fernandes et al. (2014) confirm that the more rigorous randomized research design leads to a strong decrease in effect sizes. They report a tiny partial $\mathrm{r}$ of 0.009 . Not surprisingly, when focusing on RCTs for the sub-group of low-income clients, the effect even becomes negative. Kaiser and Menkhoff (2017, Table 3) use the evidence from 44 RCT studies and report that the effect size of considered low-income clients is by -0.066 smaller than the overall effect found in RCT studies.

The advantage of meta-analysis is that they give a comprehensive picture and lead to a better understanding of the variation of existing results in the literature, but they may not be helpful when looking for the "true" effect. Given that "most published research findings are false" (Ioannidis (2005)), a meta-analysis runs the risk of just reflecting and propagating common misspecifications in existing research papers ${ }^{13}$, Koetse et al. (2013) have run Monte Carlo simulations to analyze the effects of these misspecifications on results of a meta-analysis. When researchers try to identify a "true" effect rather than summarizing the prevailing variation in outcomes, Koetse et al. (2013) show the effectiveness of including dummy variables to control for obvious primary study misspecification.

Somewhat surprisingly, except hinting at the differences between RCT and NonRCTs, misspecification does not seem to play a prominent role in the meta-study by Kaiser and Menkhoff (2017). Fernandes et al. (2014) distinguish between OLS and 2SLS results and they address the problem of the omitted variable bias by conducting three additional primary data studies (but they do not cover misspecification in the meta-analysis itself). In the discussion paper by Kaiser and Menkhoff (2017), so far there is no mention of expressions like "endogeneity", "omitted variables" or "2SLS" which could potentially be associated with the analysis of misspecification and its consequences.

Thus, even evidence from rich meta-studies does not free us from having a deeper look at single papers and reported effects by target group, estimation method and model specification.

\footnotetext{
${ }^{13}$ For instance, Bruns et al. (2014) show the misleading consequences of the common practice of overfitting in small samples for meta-analytic studies. In a meta-analysis of the validity of the deterrence hypothesis, Dölling et al. (2009) point out that estimations change considerably by choice of control variables.
} 


\subsection{Empirical Findings by Targeted Groups}

Considering the fact that financial education interventions are usually aimed at improving the welfare of disadvantaged groups, we organize this subsection by the target groups. More specifically, we review studies on financial education and the immigrants/migrants, the low-income earners and the young. A study is picked only when the intervention is explicitly targeted at the corresponding group.

We find that studies using large-scale samples are mostly on financial education and the young, while the number of studies on financial education and immigrants is still small but increasing. Financial education targeted at the low-income group has been implemented more often in less-developed countries. Our list is not complete but rather a suggestive selection of studies and only published studies are selected. Other research under the scope but not listed includes studies on the effects of financial education on women (Goldsmith and Goldsmith (2006), Field et al. (2010), financial education at the workplace (Bernheim and Garrett (2003), Drexler et al. (2014)); financial education on selected participants (Agarwal et al. (2009), Skimmyhorn et al. (2016), etc.).

A quick look from Table 1 to Table 3 reveals that there are two main methodological approaches to study the effects of financial education on the disadvantaged groups. The first one is the use of randomized controlled trials (RCT) to identify the causal effects of an intervention by randomly assigning it to the participants. The second one is to apply thorough econometric techniques to disentangle the causal effects of quasi-experiments of financial education interventions. Usually, the former method covers a smaller sample size, given the costs of implementing RCTs.

As addressing the target group of immigrants requires more effort than addressing school students, studies on the former group are based on relatively small samples, and they use more often RCTs than econometric techniques, which would require larger sample sizes. All of the selected studies on financial education and migrants and immigrants (Table 1) employ the RCT method. Many studies focus on the effects on remittance behavior. The reason for this increasing attention to the topic could be that remittance flows to developing countries become more significant, as documented by studies like Mohapatra et al. (2011) and Doi et al. (2014).

Seshan and Yang (2014) and Gibson et al. (2014) find significant effects of financial education neither on remittance behavior nor on savings, and also Barcellos et al. (2016) only report a short-lived impact fading away after about six months. 
Results by Doi et al. (2014) suggest that it might matter whether the program makes use of family peer effects or not. Their interesting finding is that training both the migrant and the family member of the worker who would be responsible for receiving remittances together has large and significant impacts on knowledge, behavior, and savings. Training the migrant only has very little impact on remaining family members.

To improve the welfare of low-income earners is often on the agenda of policy makers. Also (central) banks care about the economic status of the low-income group to avoid defaults on credit files and to stabilize the economy. Accordingly, policy makers (e.g., Grinstein-Weiss et al. (2015)) and financial institutions (see, e.g., Hartarska and Gonzalez-Vega (2005), Agarwal et al. (2009)) are motivated to implement intensive financial educational programs targeted at this disadvantaged group. In those studies, financial education counselling programs are often provided to people who are identified to be in rather poor economic conditions, and econometric techniques such as the propensity score matching are applied to estimate the effects. Almost all of the studies in Table 2, except the one by Collins (2013), find that financial education interventions have positively significant effects on the lowincome earner's saving and default rates. Collins (2013) detects significant effects for self-reported behavior, which, however, do not correspond with actual behavior as savings or credit behavior do not change substantially.

Table 3 summarizes some studies on financial education and the young. Most studies find significant, even long-term, effects of financial education (e.g., Batty et al. (2015) and Brown et al. (2016)). There are more studies on this topic but not included for reasons of brevity. More strictly speaking, the young should not be called "disadvantaged" per se, as "youth" is a transient period of everyone's life. None of the studies included in our Tables explicitly focuses on the more disadvantaged subgroup of young people.

However, as emphasized by Atkinson and Messy (2015) and OECD (2017), the young are also one of the at-risk segments of the population, and attitudes and routines developed during youth and adolescence seem to strongly influence adult financial well-being or disadvantage. Also, theoretical contributions based on life cycle models (see above) suggest that financial education on the young could improve the social welfare of members of disadvantaged families over a lifetime and, thus, might reduce economic inequality. Another reason why we care about financial education and the young is that large-scale financial education interventions are accessible to policy makers and appealing to scholars, although the discussion on 
the upsides and downsides of those interventions is still open. 


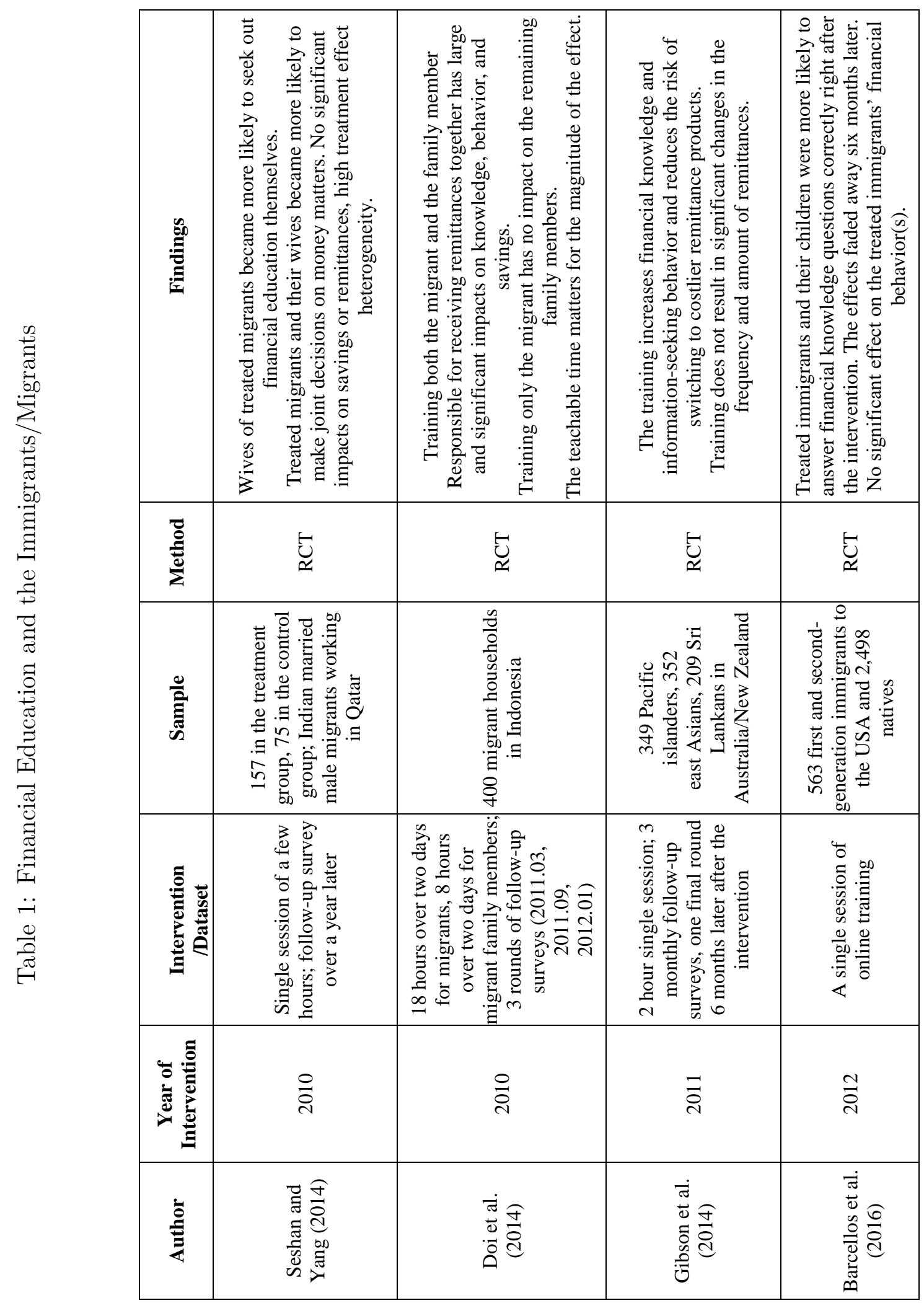




\begin{tabular}{|c|c|c|c|c|}
\hline 总 & 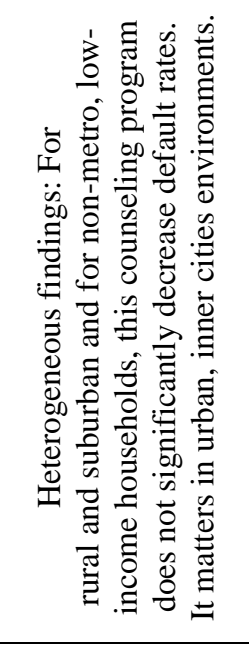 & 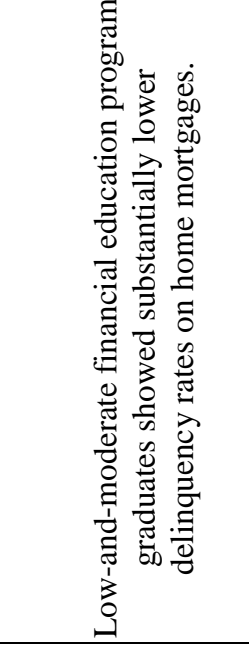 & 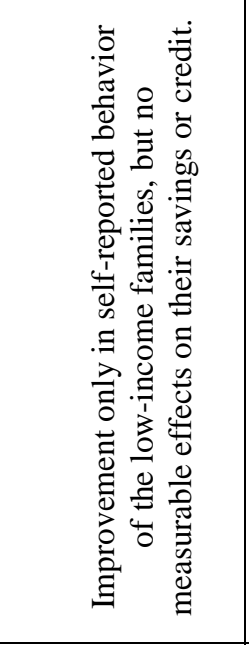 & 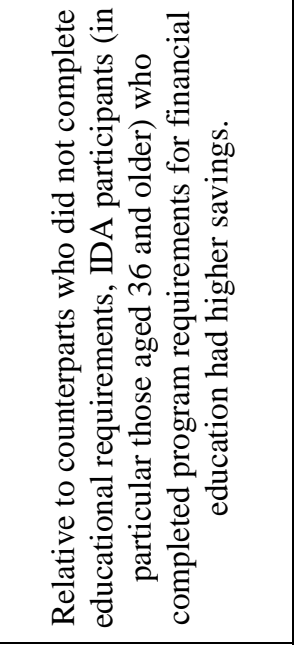 \\
\hline & 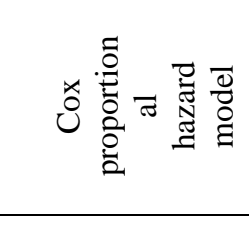 & 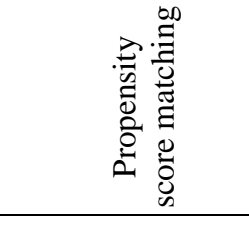 & 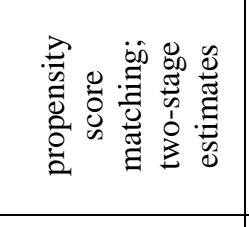 & 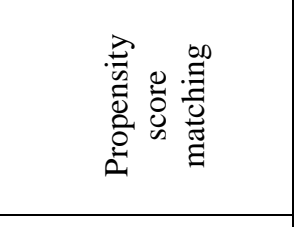 \\
\hline 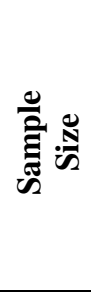 & 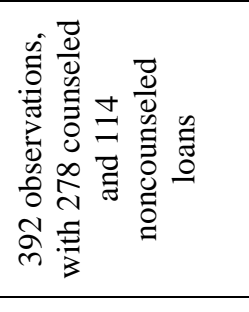 & 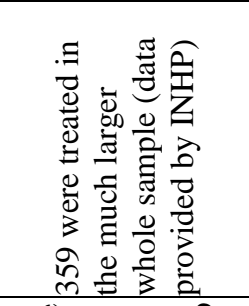 & 声 & $\begin{array}{l}\text { 袁 } \\
\text { i }\end{array}$ \\
\hline 赔 & 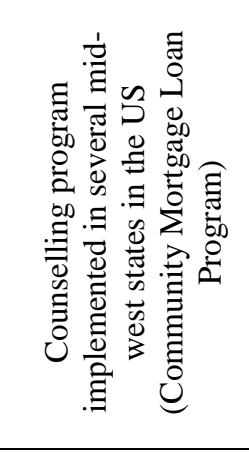 & 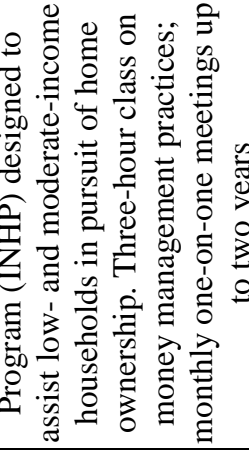 & 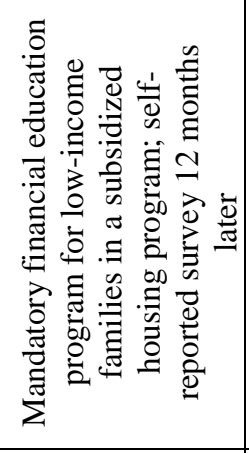 & 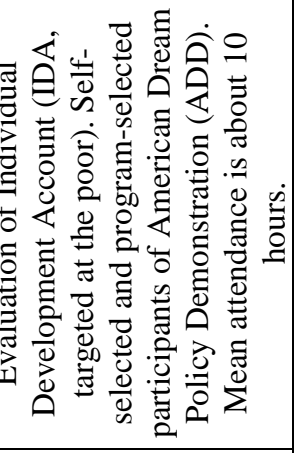 \\
\hline 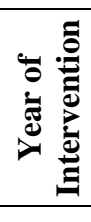 & Sू' & 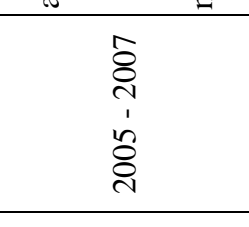 & $\stackrel{\tilde{d}}{0}$ & 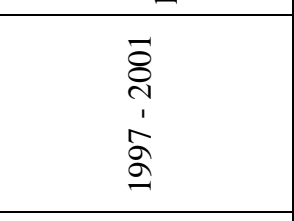 \\
\hline 颜 & 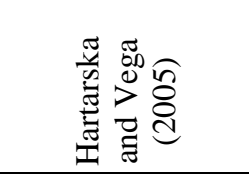 & 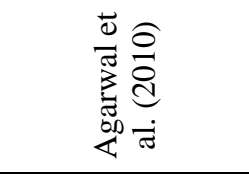 & 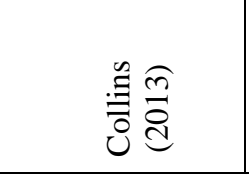 & 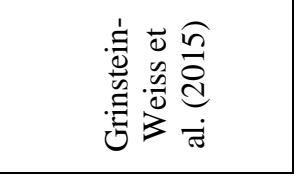 \\
\hline
\end{tabular}




\begin{tabular}{|c|c|c|c|}
\hline 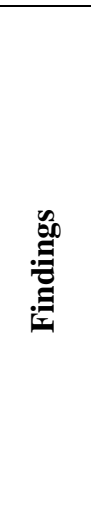 & 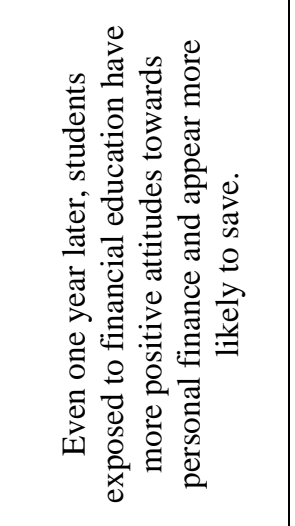 & 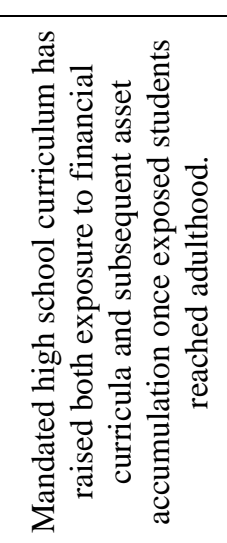 & 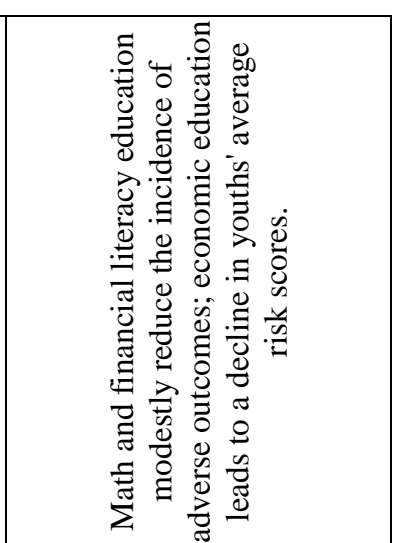 \\
\hline 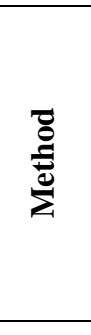 & $E_{\mathscr{L}}$ & 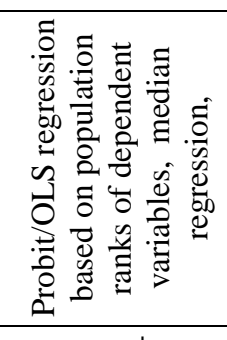 & 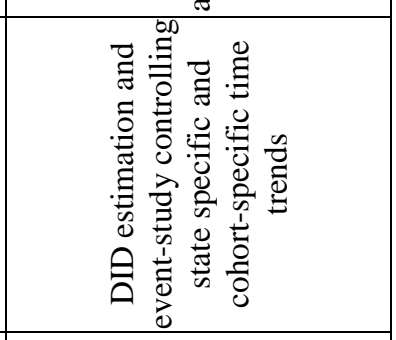 \\
\hline 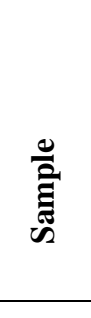 & 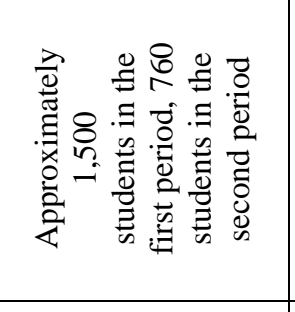 & 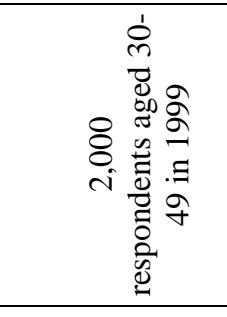 & 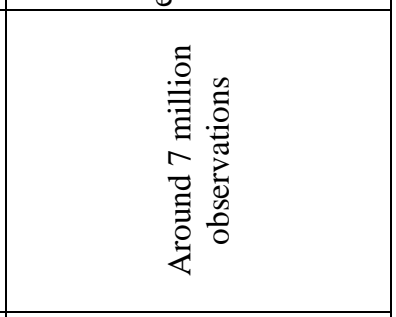 \\
\hline 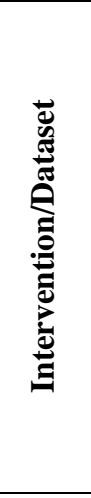 & 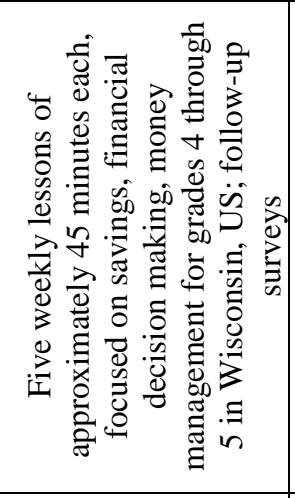 & 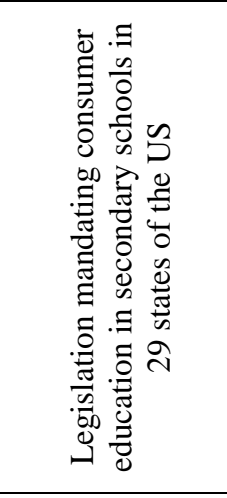 & 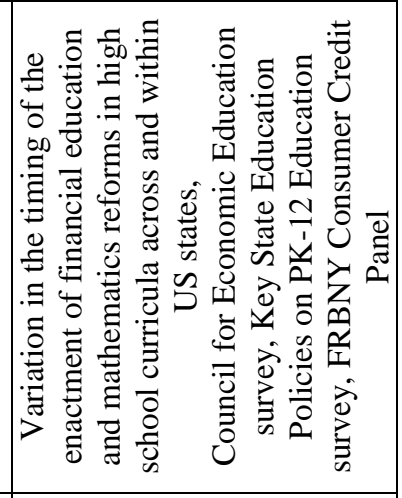 \\
\hline 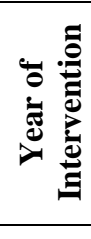 & 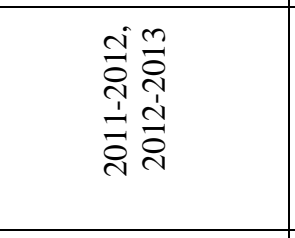 & 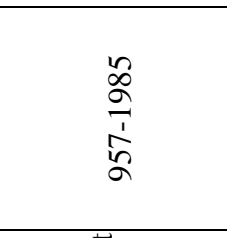 & 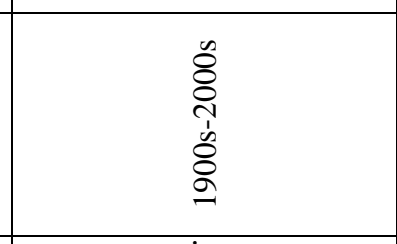 \\
\hline 咅 & 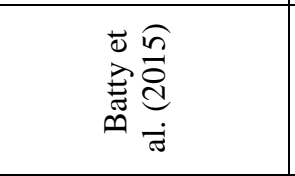 & 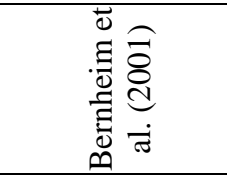 & 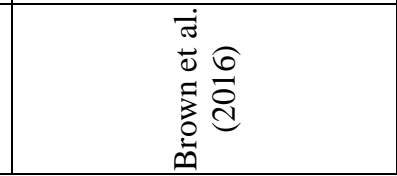 \\
\hline
\end{tabular}




\begin{tabular}{|c|c|c|c|}
\hline$\stackrel{\mathscr{E}}{: 0}$ & 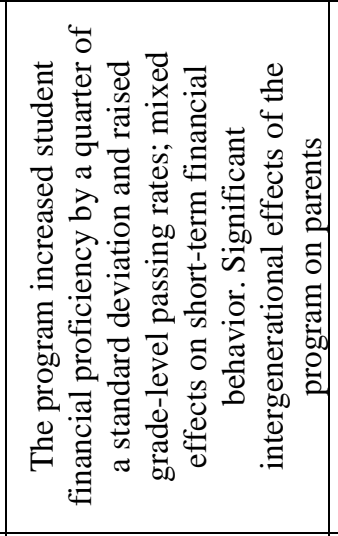 & 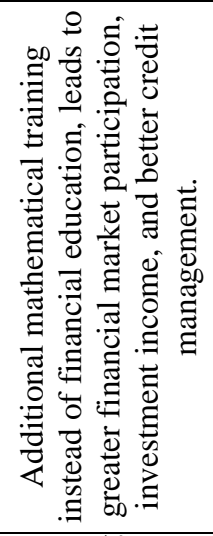 & 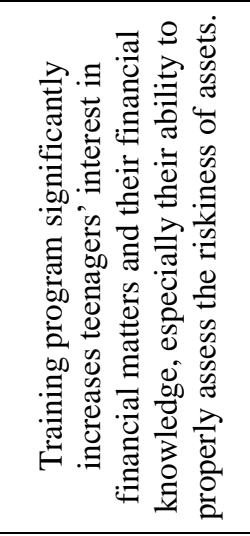 \\
\hline 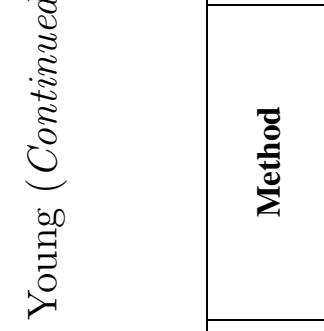 & $\underset{\simeq}{\underline{\sim}}$ & 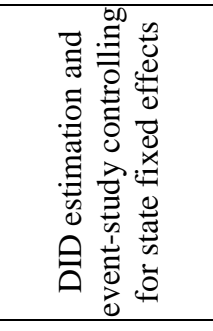 & $\underset{\simeq}{E}$ \\
\hline 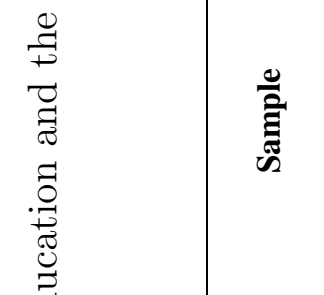 & 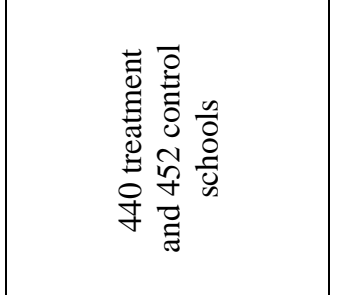 & 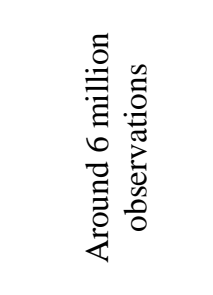 & 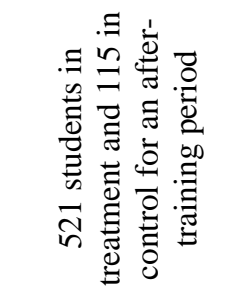 \\
\hline 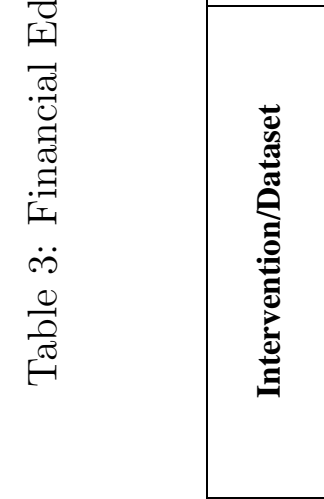 & 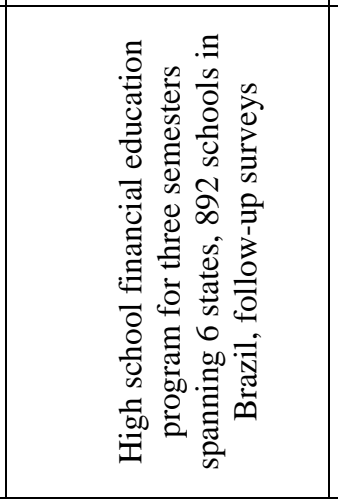 & 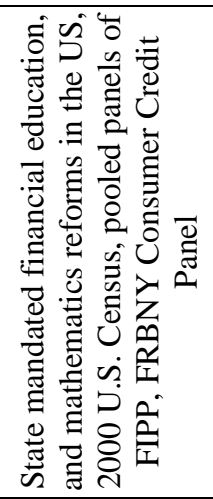 & 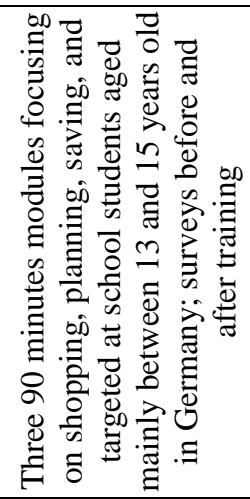 \\
\hline 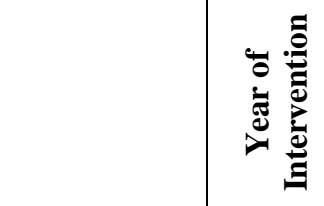 & 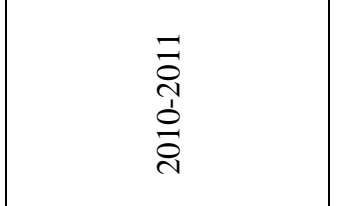 & 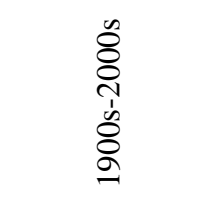 & $\stackrel{\sim}{\stackrel{\sim}{\sim}}$ \\
\hline$\stackrel{\grave{\Xi}}{E}$ & 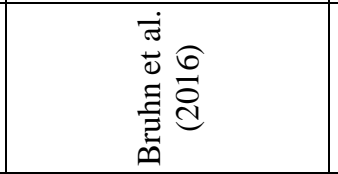 & $\begin{array}{l}\dot{\sigma} \\
\stackrel{0}{0} \\
\frac{0}{0} \\
\dot{0} \\
0\end{array}$ & 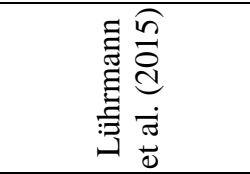 \\
\hline
\end{tabular}




\subsection{Common Issues in RCTs}

It is perhaps not surprising to find even less significant effects of financial education on immigrants/migrants than on low-income earners, as reported RCT interventions for migrants and immigrants summarized in Table 1 are shorter and less intensive than those for low-income groups summarized in Table 2. To avoid unobserved bias caused by more intensive and lasting interventions, such as a decreasing participation rate, changing characteristics of participants (Glewwe (2002)) and too much variety of teaching materials, it would indeed be favorable to apply shorter sessions of financial education through more controlled methods. The downside of the purity of RCTs is that the education interventions were possibly too weak and short such that they kept below a critical threshold of efficacy.

Different from the smaller samples in RCTs on financial education and immigrants/migrants, RCTs applied to the young, especially to school students, can be much easier applied to larger samples and based on more intensive treatment. Remarkable examples are Berry et al. (2015) for Ghana, Bjorvatn et al. (2015) for Tanzania, Lührmann et al. (2015) for Germany, Batty et al. (2015) for the U.S., and Becchetti and Pisani (2011) and Becchetti et al. (2013) for Italy. Likewise in contrast to RCT results found for immigrants/migrants, many studies report positive significant effects, for instance on students' attitudes regarding personal financial and saving behavior (Batty et al. (2015)), financial proficiency (Bruhn et al. (2016)) or financial knowledge and risk aversion (Lührmann et al. (2015)).

As also pointed out by Glewwe (2002), RCTs can be the ideal way to identify the causal effects of financial education on economic behaviors, given proper randomization. He highlights the sample selection issue as potential caveat. Bruhn et al. (2013) indicate that one common issue faced by all small-scale RCTs is that the selection of participants is usually based on a voluntary process, and the voluntary participation is typically low.

For example, the RCT on migrants from Indonesia in Doi et al. (2014) seems to be faced with the sample selection issue. The randomized selection process started with a diagnostic study to identify a region with a high concentration of migrants (East Java), the sample was organized by Malang's Manpower and Transmigration Office, and the participants have been selected by a privately-owned Indonesian Manpower Placement Company. The process ended up with almost all participants being female which reflects the common existence of non-unitary households with women deciding on daily spending. A further issue is that no information was given 
on the response ratio of people who agreed to participate to people who were invited. In addition, those who participated were selected from those who were still staying in the dormitory facilities of the recruitment agencies or lived close by. Thus, it seems rather problematic to extract external validity from the study - but this a rather general problem with many other RCT studies and not limited to Doi et al. (2014), as emphasized by Cartwright (2007) and Deaton and Cartwright (in press). RCT, too, is no gold standard.

Gibson et al. (2014) spend a lot of effort on designing the content of the intervention in Australia, and on assuring that the educational content is sufficiently accessed by participant:14, Follow-up surveys were conducted for multiple times, which allows them to examine the dynamic effects of the educational intervention ${ }^{15}$ The intervention was carefully designed in many aspects. However, the participants were not selected in a randomized way but rather through social networks. For example, one third of Pacific Island participants were recruited from a Pacific cultural festival, and the rest were from the main Pacific outdoor market or churches. Besides that, all participants were drawn from Hamilton and Auckland, and no evidence indicates that this is a randomized draw for a well-defined population. On the positive side, the experiment represents an innovative approach for how to implement a financial education intervention for migrants with low costs.

A similar ambiguity exists in Barcellos et al. (2016) on financial literacy targeted at immigrants in the US, even though much effort has been invested to assure the randomization of the sample as much as possible, and to enable reasonable interpretations of results. However, as also mentioned by the authors themselves, the interpretation is limited by the small sample size (135 in treatment group 1, 118 in treatment group 2 and 117 in the control group, only 330 in the follow-up survey), and by attrition problems. Besides that, the participants are recruited from an Internet panel of respondents 18 years and older who agreed to participate in occasional online surveys. This self-selection bears the risk of receiving responses from a particular (unknown) subgroup of the population, once again questioning the external validity of results. Moreover, there were two sets of financial educational materials targeted at immigrants/migrants which were released to treatment groups online, but no clear description on the heterogeneity of the training intensity was given, i.e., how much time participants spent on the material for their training

\footnotetext{
${ }^{14}$ Written materials were provided to trainees; one training session was two hours and usually held at churches, community centers, and sports clubs for 30 people at one time.

${ }^{15}$ Monthly follow-up surveys were conducted for the three months after the training intervention to capture the short-time effects of the training intervention. One more follow-up survey was done in the sixth month after the training, to measure its long-term effects.
} 
sessions. A particular problem seems to be the large variety of English language skills. Those with poor skills underperform because the survey questions were put in English such that any test of financial knowledge is at the same time an English proficiency test and measures language gaps. This joint hypotheses test makes it difficult to identify the "true" effect of financial education because test results are blurred by the heterogeneity of language skills.

Looking at Glewwe (2002)'s list of potential problems with RCTs, the two issues of non-stable characteristics of sampled individuals and of sample selection biases are still relevant. Even though Bruhn et al. (2016) use one of the largest samples among those targeted at the young, the RCT is still faced with both problems. In regard to the first issue, there is not much information about whether parents of the "treated" students decrease their efforts to support the students during the training period or not. In terms of the second issue, the description of the study shows that the RCT is well designed, but there is still much ambiguity about the implementation process of the program. The RCT was implemented in public high schools in Brazil. 892 public high schools and approximately 25,000 students from the Federal District, and 5 out of 26 states are involved. The Secretariat of Education in each state assembled a list of schools willing to participate in the program. Several steps were applied to assure the randomization of the assignment ${ }^{16}$. However, we do not have information about whether there were parents who enrolled their children into the treatment group in the course of the intervention. Moreover, it is mentioned that also about $17 \%$ of schools in the control group have implemented some own financial education, but the authors do not know how intensive this training might have been. They presume that these programs might have been less intensive than the one studied in this paper.

\subsection{Common Econometric Issues}

When it comes to the econometric approach, Glewwe (2002) summarizes five common issues which could arise in this method. Though the topic of Glewwe (2002) is on general education programs in developing countries, addressed problems also hold for financial education programs: (1) considering the unobserved components

\footnotetext{
${ }^{16}$ The randomization of assigning schools to treatment groups and control groups was done by the research team through a computer, but small adjustments were done manually due to administration requirements or other reasons. A stratification method was implemented to make the sample representative of public schools in terms of the quality of the school. Besides, GDP and savings volume per capita of the municipality, school location, number of students and teachers in the school, school drop-out rate, school graduation rate are balanced across the treatment and control groups.
} 
of the participants, such as factors on motivation, inner ability; (2) omitted variables, for example, the instructors' quality; (3) sample selection, when people with disadvantaged family background might have fewer chances to attend schools offering curricula with mandated financial education; (4) endogeneity of participating in a financial education intervention, for example if people with lower wealth might be less motivated to attend the intervention; (5) measurement error in the regressors and improper specification of the dependent variable.

A good example to address the importance of econometric issues is shown by the comparison of two studies on financial education and the young, i.e., Bernheim et al. (2001) and Cole et al. (2016). Both studies investigate the effects of the same financial educational intervention but arrive at completely different conclusions. The financial education intervention under investigation by Bernheim et al. (2001) is a national mandatory "consumer" education intervention in secondary schools in the U.S. 29 states adopted it during the time period 1957 to 1985. Bernheim et al. (2001) use a cross-sectional household survey conducted in fall 1995 to identify longterm effects of the mandatory intervention on households' saving behavior. Careful empirical modeling, including a difference-in-difference approach, and robustness checks have been conducted to assure the reliability of the model. However, the significantly positive effects found in Bernheim et al. (2001) are "washed out" by simply adding state fixed effects in Cole et al. (2016). Cole et al. (2016) admit that the difference might come from the difference of data sources, but they provide econometric evidence showing that this is not the reason. But Cole et al. (2016) are not perfect either. No obviously convincing evidence has shown that the systematic differences of effects between states (leading to the significance of state fixed effects and usually attributed to unknown third factors of some sort) do not reveal the heterogeneity of efficacy of state-specific financial education mandates (such that the state-fixed effect would "throw out the baby with the bath water").

Despite the critical assessment in later research, the paper by Bernheim et al. (2001) can be considered as seminal. It had a strong impact on future work on the effects of financial education on financial behavior such as savings. It also presents one of the first studies examining the causal effects of financial education on certain economic behaviors. Cole et al. (2016) leave us even more skeptical about the reliability and validity of results, not only with respect to Bernheim et al. (2001) but also in more general terms. The comparison of the two papers reveals that the choice of methodology matters a lot. In order to get a less biased estimation, authors need to find the most suitable technique, adapted to the institutional context and the nature of the data. There is not one silver bullet which could be used for all 
potential research questions on the effect of financial education.

In sum, we need to conclude that there is no satisfying answer to the question of what is the best way of testing the impact of financial education, RCT or the econometric approach. RCT has become the more popular approach in recent years, but tides might be turning. As pointed out by Deaton and Cartwright (in press): "At best, RCT yields an unbiased estimate, but this property is of limited practical value. Even then, estimates apply only to the sample selected for the trial, often no more than a convenience sample, and justification is required to extend the results to other groups". RCT is a fine technique to study the causal effects of financial education, and it is very popular when the targeted groups are the immigrants/migrants and the young, but results depend on the pre-selected and reachable sub-population of the randomization process and the treatment. Financial education interventions are way far from being consistent and comparable with each other.

On the other hand, empirical results from using non-RCTs are also mixed, and not necessarily superior to the RCT approach. But there is evidence that the applied econometric approach is getting more mature. For example, in addition to common controls like age and gender, other relevant elements like personal motivation (Mandell and Klein (2009)) or time preferences (Meier and Sprenger (2015)) are taken into consideration. On the methodological side, there is new literature (reviewed by Belloni et al. (2017) and Athey and Imbens (2017) among others) proposing machine learning techniques or high-dimensional settings, which aim to develop estimation and inference tools in program evaluation allowing for a large number of control variables (much larger than the sample size). However, at the present stage, it is too early to say anything about the usefulness in practical applications.

The lesson to be learned is that diverse research methods should be combined in a reasonable way such that evaluation studies can play a role in building scientific knowledge. RCTs have the potential to estimate clean average treatment effects, but in order to be comparable with each other they need to adjust for particularities in institutional settings and include prior knowledge. Investigations also need to build on theoretical work, and conclusions should go beyond simple statements on "what works", but "why things work" (Deaton and Cartwright (in press)). 


\section{Concluding Remarks}

Financial policy worldwide welcomes and embraces initiatives to improve financial literacy. Financial education programs are considered as suitable measures to develop the knowledge, skills, and ability to make safe financial decisions and to increase resilience against future financial shocks. As many scholars and politicians see social inequality as the source of the 2008 financial crisis (known as the Rajan hypothesis, inspired by Rajan (2011)), and because financial education and financial literacy are seen as the key to solve the problem of unequal chances, our survey has a focus on the group at the bottom of the financial wealth distribution. However, in sharp contrast to the popularity of financial education interventions, studies on the effectiveness of interventions show mixed results for the disadvantaged groups under consideration, and particularly for the group of migrants almost no sustainable impact on financial behavior has been detected and reported by the literature.

Our survey reviews both the theoretical and empirical findings in order to understand why this discrepancy exists. The survey first highlights the problematic link between financial education, financial literacy and financial behavior in the existing literature, and discusses the importance of third factors such as cognitive ability, mathematical capability or numeracy. Theories on financial literacy help us to understand the heterogeneous effect of interventions across the population and over the life cycle which in turn could lead to better identification, targeting and implementation of pinpointed financial education interventions.

Looking at empirical results, we find that the young, the immigrants/migrants and the low-income groups obtain more attention from scholars than other disadvantaged groups. Studies on large-scale samples, both using RCTs and econometric methods for quasi-experiments, show up more often for investigating financial education on the young. The effect on remittance behavior is the focus in studies on samples of migrants. Some support in favor of financial education for the young has been detected in terms of higher short-term financial knowledge and awareness in some studies, but there is no proven evidence of improved long-term behavior after growing up. From the methodological point of view, despite the criticism brought forward by Deaton and Cartwright (in press) and others, RCT has become a popular approach to evaluate the effect of financial education in recent years, in particular for studies on remittance behavior of migrants. Results based on RCT reveal even smaller effects than those based on the econometric approach. Our survey discusses some limitations of both RCTs and econometric studies which might be taken into account by future research. We conclude that further standardizations of RCTs 
would enhance the information transparency and comparability of results from evaluation studies. Moreover, we give a critical assessment of meta-analytic insights regarding financial education which bear the risk of just reflecting and propagating common misspecifications in existing research papers.

In sum, despite the enthusiasm of politicians, who see financial education and financial literacy as the key to tackle the problem of financial vulnerability, so far, there is no clear evidence, or at least no scientific consensus, on the effectiveness of interventions. The financial education fallacy addressed by Willis (2011) alerts us that the constant search for effective financial education might cost enormously such that the costs of financial education programs might outweigh potential benefits. Even if people promoting financial education don't agree with Willis (2011), they should have second thoughts before spending scarce governmental resources. It is perhaps true that the financial behavior of the poor is arguably more controlled by lack of aspirations such that financial policy should be directed towards behaviorally motivated anti-poverty policies (as described by Bertrand et al. (2004)).

Given our approach to the literature, a limitation of the survey is that we cannot review all the studies of interest in detail. Besides, we do not examine the interventions by countries, although country and state-specific heterogeneity might also be important to understand the effectiveness of financial education programs for disadvantaged groups. 


\section{References}

Agarwal, S., P. M. Skiba, and J. Tobacman (2009). Payday loans and credit cards: New liquidity and credit scoring puzzles? The American Economic Review 99(2), $412-417$.

Arrow, K. J. (1987). The demand for information and the distribution of income. Probability in the Engineering and Informational Sciences 1(1), 3-13.

Athey, S. and G. W. Imbens (2017). The state of applied econometrics: Causality and policy evaluation. Journal of Economic Perspectives 31(2), 3-32.

Atkinson, A. and F. Messy (2015). Financial education for migrants and their families. Technical report, OECD Publishing.

Attanasio, O. P. (1999). Consumption. Handbook of macroeconomics 1, 741-812.

Barcellos, S. H., L. S. Carvalho, J. P. Smith, and J. Yoong (2016). Financial education interventions targeting immigrants and children of immigrants: Results from a randomized control trial. Journal of Consumer Affairs 50(2), 263-285.

Batty, M., J. M. Collins, and E. Odders-White (2015). Experimental evidence on the effects of financial education on elementary school students' knowledge, behavior, and attitudes. Journal of Consumer Affairs 49(1), 69-96.

Becchetti, L., S. Caiazza, and D. Coviello (2013). Financial education and investment attitudes in high schools: Evidence from a randomized experiment. Applied Financial Economics 23(10), 817-836.

Becchetti, L. and F. Pisani (2011). Financial education on secondary school students: The randomized experiment revisited. Econometica Papers wp34, Econometica.

Belloni, A., V. Chernozhukov, I. Fernández-Val, and C. Hansen (2017). Program evaluation and causal inference with high-dimensional data. Econometrica 85(1), 233-298.

Ben-Porath, Y. (1967). The production of human capital and the life cycle of earnings. Journal of Political Economy 75(4, Part 1), 352-365.

Bernheim, B., D. M. Garrett, and D. M. Maki (2001). Education and saving: The long-term effects of high school financial curriculum mandates. Journal of Public Economics 80(3), $435-465$.

Bernheim, B. D. and D. M. Garrett (2003). The effects of financial education in the workplace: Evidence from a survey of households. Journal of Public Economics $87(7)$, 1487-1519. 
Berry, J., D. Karlan, and M. Pradhan (2015). The impact of financial education for youth in Ghana. WorkingPaper 15-043/V, Tinbergen Institute.

Bertrand, M., S. Mullainathan, and E. Shafir (2004). A behavioral-economics view of poverty. American Economic Review 94(2), 419-423.

Bjorvatn, K., A. W. Cappelen, L. H. Sekei, E. Sorensen, and B. Tungodden (2015). Teaching through television: Experimental evidence on entrepreneurship education in Tanzania.

Brown, M., J. Grigsby, W. van der Klaauw, J. Wen, and B. Zafar (2016). Financial education and the debt behavior of the young. The Review of Financial Studies 29(9), 2490-2522.

Bruhn, M., L. de Souza Leão, A. Legovini, R. Marchetti, and B. Zia (2016). The impact of high school financial education: Evidence from a large-scale evaluation in Brazil. American Economic Journal: Applied Economics 8(4), 256-295.

Bruhn, M., G. L. Ibarra, and D. McKenzie (2013). Why is voluntary financial education so unpopular? Experimental evidence from Mexico. Technical report, The World Bank.

Bruns, S. B., C. Gross, and D. I. Stern (2014). Is there really granger causality between energy use and output? The Energy Journal 35(4), 101-133.

Campbell, J. Y. (2006). Household finance. The Journal of Finance 61(4), 15531604.

Cartwright, N. (2007). Are RCTs the gold standard? BioSocieties 2(1), 11-20.

Cohen, A. (1992). Antecedents of organizational commitment across occupational groups: A meta-analysis. Journal of Organizational Behavior 13(6), 539-558.

Cole, S., A. Paulson, and G. K. Shastry (2014). Smart money? The effect of education on financial outcomes. The Review of Financial Studies 27(7), 20222051.

Cole, S., A. Paulson, and G. K. Shastry (2016). High school curriculum and financial outcomes: The impact of mandated personal finance and mathematics courses. Journal of Human Resources 51(3), 656-698.

Collins, J. M. (2013). The impacts of mandatory financial education: Evidence from a randomized field study. Journal of Economic Behavior $\mathscr{6}$ Organization 95, $146-158$. 
Collins, J. M. and C. M. O'Rourke (2010). Financial education and counseling - still holding promise. Journal of Consumer Affairs 44(3), 483-498.

Cunha, F. and J. Heckman (2007). The technology of skill formation. American Economic Review 97(2), 31-47.

Deaton, A. and N. Cartwright (in press). Understanding and misunderstanding randomized controlled trials. Social Science \& Medicine.

Delavande, A., S. Rohwedder, and R. J. Willis (2008). Preparation for retirement, financial literacy and cognitive resources. Technical report, University of Michigan Retirement Reesearch Center Working Paper 2008-190.

Disney, R. and J. Gathergood (2013). Financial literacy and consumer credit portfolios. Journal of Banking \& Finance 37(7), 2246-2254.

Doi, Y., D. McKenzie, and B. Zia (2014). Who you train matters: Identifying combined effects of financial education on migrant households. Journal of Development Economics 109, 39-55.

Dölling, D., H. Entorf, D. Hermann, and T. Rupp (2009). Is deterrence effective? Results of a meta-analysis of punishment. European Journal on Criminal Policy and Research 15(1-2), 201-224.

Drexler, A., G. Fischer, and A. Schoar (2014). Keeping it simple: Financial literacy and rules of thumb. American Economic Journal: Applied Economics 6(2), 1-31.

Fernandes, D., J. G. Lynch Jr, and R. G. Netemeyer (2014). Financial literacy, financial education, and downstream financial behaviors. Management Science 60(8), 1861-1883.

Field, E., S. Jayachandran, and R. Pande (2010). Do traditional institutions constrain female entrepreneurship? A field experiment on business training in india. American Economic Review 100(2), 125-29.

Gathergood, J. (2012). Self-control, financial literacy and consumer overindebtedness. Journal of Economic Psychology 33(3), 590-602.

Gibson, J., D. McKenzie, and B. Zia (2014). The impact of financial literacy training for migrants. The World Bank Economic Review 28(1), 130-161.

Glewwe, P. (2002). Schools and skills in developing countries: Education policies and socioeconomic outcomes. Journal of Economic Literature 40(2), 436-482. 
Goldsmith, R. E. and E. B. Goldsmith (2006). The effects of investment education on gender differences in financial knowledge. Journal of Personal Finance 5(2), 55 .

Gramațki, I. (2017). A comparison of financial literacy between native and immigrant school students. Education Economics 25(3), 304-322.

Grinstein-Weiss, M., S. Guo, V. Reinertson, and B. Russell (2015). Financial education and savings outcomes for low-income ida participants: Does age make a difference? Journal of Consumer Affairs 49(1), 156-185.

Hackethal, A., M. Haliassos, and T. Jappelli (2012). Financial advisors: A case of babysitters? Journal of Banking \& Finance 36(2), 509-524.

Hanushek, E. A. and L. Woessmann (2008). The role of cognitive skills in economic development. Journal of Economic Literature 46(3), 607-68.

Hartarska, V. and C. Gonzalez-Vega (2005). Credit counseling and mortgage termination by low-income households. The Journal of Real Estate Finance and Economics 30(3), 227-243.

Hastings, J. S., B. C. Madrian, and W. L. Skimmyhorn (2013). Financial literacy, financial education, and economic outcomes. Annual Review of Economics 5(1), $347-373$.

Hilgert, M. A., J. M. Hogarth, and S. G. Beverly (2003). Household financial management: The connection between knowledge and behavior. Fed. Res. Bull. 89, 309.

Hubbard, R. G., J. Skinner, and S. P. Zeldes (1995). Precautionary saving and social insurance. Journal of Political Economy 103(2), 360-399.

Hung, A., A. M. Parker, and J. Yoong (2009). Defining and measuring financial literacy. Technical report, RAND CorporationWorking Papers - 708.

Huston, S. J. (2010). Measuring financial literacy. Journal of Consumer Affairs 44(2), 296-316.

Ioannidis, J. P. (2005). Why most published research findings are false. PLoS medicine 2(8), e124.

Jappelli, T. and M. Padula (2013). Investment in financial literacy and saving decisions. Journal of Banking \& Finance 37(8), 2779-2792. 
Kaiser, T. and L. Menkhoff (2017). Does financial education impact financial behavior, and if so, when? Technical report, World Bank Policy Research Working Paper No. 8161.

Kézdi, G. and R. J. Willis (2008). Stock market expectations and portfolio choice of american households. work in progress.

Kézdi, G. and R. J. Willis (2011). Household stock market beliefs and learning. Technical report, National Bureau of Economic Research.

Klapper, L., A. Lusardi, and G. A. Panos (2013). Financial literacy and its consequences: Evidence from russia during the financial crisis. Journal of Banking \&6 Finance 37(10), 3904-3923.

Koetse, M., R. Florax, and H. de Groot (2013). Correcting for primary study misspecifications in meta-analysis. Technical report, Tinbergen Institute.

Lipsey, M. W. and D. B. Wilson (2001). Practical meta-analysis. Sage Publications, Inc.

Lührmann, M., M. Serra-Garcia, and J. Winter (2015). Teaching teenagers in finance: Does it work? Journal of Banking \& Finance 54, 160-174.

Lusardi, A., P.-C. Michaud, and O. S. Mitchell (2017). Optimal financial knowledge and wealth inequality. Journal of Political Economy 125(2), 431-477.

Lusardi, A. and O. S. Mitchell (2008). Planning and financial literacy: How do women fare? American Economic Review 98(2), 413-17.

Lusardi, A. and O. S. Mitchell (2011). Financial literacy around the world: An overview. Journal of Pension Economics 63 Finance 10(4), 497-508.

Lusardi, A. and O. S. Mitchell (2014). The economic importance of financial literacy: Theory and evidence. Journal of Economic Literature 52(1), 5-44.

Lusardi, A., O. S. Mitchell, and V. Curto (2010). Financial literacy among the young. Journal of Consumer Affairs 44(2), 358-380.

Mandell, L. and L. S. Klein (2009). The impact of financial literacy education on subsequent financial behavior. Journal of Financial Counseling and Planning 20(1).

McCannon, B. C., C. T. Asaad, and M. Wilson (2016). Financial competence, overconfidence, and trusting investments: Results from an experiment. Journal of Economics and Finance 40(3), 590-606. 
Meier, S. and C. D. Sprenger (2015). Temporal stability of time preferences. Review of Economics and Statistics 97(2), 273-286.

Merton, R. C. (1969). Lifetime portfolio selection under uncertainty: The continuous-time case. The Review of Economics and Statistics, 247-257.

Miller, M., J. Reichelstein, C. Salas, and B. Zia (2015). Can you help someone become financially capable? A meta-analysis of the literature. The World Bank Research Observer 30(2), 220-246.

Mohapatra, S., D. Ratha, and A. Silwal (2011). Outlook for remittance flows 201113: Remittance flows recover to pre-crisis levels.

OECD (2015a). 2015 update of the OECD/INFE toolkit for measuring financial literacy and financial inclusion.

OECD (2015b). National strategies for financial education: OECD/INFE policy handbook. Handbook, OECD.

OECD (2017). G20/OECD INFE report on ensuring financial education and consumer protection for all in the digital age. Technical report, OECD.

Rajan, R. G. (2011). Fault lines: How hidden fractures still threaten the world economy. Princeton University press.

Scholz, J. K., A. Seshadri, and S. Khitatrakun (2006). Are Americans saving "optimally" for retirement? Journal of Political Economy 114(4), 607-643.

Schuhen, M. and S. Schürkmann (2014). Construct validity of financial literacy. International Review of Economics Education 16, 1-11.

Seshan, G. and D. Yang (2014). Motivating migrants: A field experiment on financial decision-making in transnational households. Journal of Development Economics 108, 119-127.

Skimmyhorn, W. et al. (2016). Assessing financial education: Evidence from boot camp. American Economic Journal: Economic Policy 8(2), 322-343.

Van Rooij, M., A. Lusardi, and R. Alessie (2011). Financial literacy and stock market participation. Journal of Financial Economics 101(2), 449-472.

Von Gaudecker, H.-M. (2015). How does household portfolio diversification vary with financial literacy and financial advice? The Journal of Finance 70(2), 489507.

Willis, L. E. (2008). Against financial-literacy education. Iowa L. Rev. 94, 197. 
Willis, L. E. (2011). The financial education fallacy. American Economic Review $101(3)$, 429-34.

Xu, L. and B. Zia (2012). Financial literacy around the world: An overview of the evidence with practical suggestions for the way forward. Policy Research Working Paper Series 6107, The World Bank. 


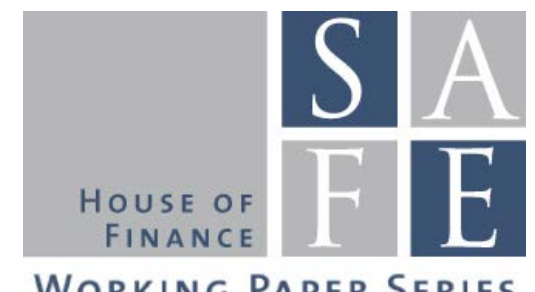

WORKING PAPER SERIES

\section{Recent Issues}

No.204 Loriana Pelizzon, Matteo

Sottocornola

No. 203 Florian Hett, Felix Schmidt

No. 202 Tobias H. Tröger

No. 201 Dirk Krueger, Alexander Ludwig

No. 200 Nils Grevenbrock, Max Groneck, Alexander Ludwig, Alexander Zimper

No. 199 Tobias H. Tröger

No. 198 Henning Hesse, Boris Hofmann, James Weber

No. 197 Benjamin Clapham, Peter Gomber, Martin Haferkorn, Paul Jentsch, Sven Panz

No. 196 Benjamin Clapham, Peter Gomber, Sven Panz

No. 195 Benjamin Clapham, Peter Gomber, Martin Haferkorn, Sven Panz

No. 194 Baptiste Massenot

No. 193 Mario Bellia, Roberto Panzica, Loriana Pelizzon, Tuomas Peltonen

No. 192 Vincenzo Pezone

No. 191 Julia Hirsch, Uwe Walz
The Impact of Monetary Policy Interventions on the Insurance Industry

Pushing Through or Slacking Off? Heterogeneity in the Reaction to Rank Feedback

Germany's Reluctance to Regulate Related Party Transactions

Optimal Taxes in the OLG Model with Uninsurable Idiosyncratic Income Risk

Cognition, Optimism and the Formation of Age-Dependent Survival Beliefs

Regulation of Crowdfunding in Germany

The Macroeconomic Effect of Asset Purchases Revisited

Circuit Breakers - A Survey among International Trading Venues

Coordination of Circuit Breakers? Volume Migration and Volatility Spillover in Fragmented Markets

Managing Excess Volatility: Design and Effectiveness of Circuit Breakers

A Business Cycle Model with Neuroeconomic Foundations

The Demand for Central Clearing: To Clear or Not to Clear, That is the Question

The Real Effects of Judicial Enforcement: Evidence from Italy

Financial constraints, newly founded firms and the financial crisis 